\title{
Three Body Abrasive Wear Behaviour of Polyamide 66/ Polypropylene (PA66/PP) Thermoplastic Blends
}

\author{
Lingesh B V ${ }^{*}$, Ravikumar B N ${ }^{1}$, Rudresh B M ${ }^{2}$ \\ ${ }^{1}$ Department of Mechanical Engineering, Bangalore Institute of Technology, Bangalore-560004, India \\ ${ }^{2}$ Department of Mechanical Engineering, Government Engineering College, K R Pet- 571426, India \\ * Corresponding author email: blingesh@gmail.com
}

Received: 24 January 2017 / Accepted: 29 January 2017 / Published: 3 February 2017

\begin{abstract}
Three body abrasive wear behaviour of Polyamide 66 and Polypropylene (PA66/PP) blends in different weight percentages of $95 / 5,90 / 10,85 / 15,80 / 20,75 / 25$ and $70 / 30$ are investigated. The experiments were carried out as per ASTM G65 by using rubber wheel abrasion tester (RWAT). The tests were conducted for a load of 50 and $75 \mathrm{~N}$ at a sliding velocity of $2.5 \mathrm{~m} / \mathrm{s}$ with an abrading distance of 500 , 1000 and $1500 \mathrm{~m}$ using fine abrasive dry sand particles as third body. The experimental results revealed that the wear volume and specific wear rate are the functions of load, abrading distance and composition of blend. It was observed from the experimentation that the lower loading of PP into blend decreases the wear resistance. The effective wear resistance starts from higher loading of PP (30 wt. $\%)$ in the blend. The abrasive sand particles and their size played a major role in determining the wear characteristics of PA66/PP blends. Substantiate amount of rubber wheel wear contributes to the development of wear resistance. The worn surfaces are studied by using Scanning Electron Microscope (SEM) photographs.

Keywords: PA66/PP Blends; Three body; Abrasion; Thermoplastic
\end{abstract}

\section{Introduction}

The mechanical industries are propelling towards polymeric materials due to their smart performance at critical conditions. They are light in weight, self-lubricative, environmental friendly, fairy appearance, good specific modulus and strength. Polymers, in particular thermoplastics are one such group of materials which can be competitive to these environments. Polymers and their composites are being used in industries like bearings, gears, automobiles and aerospace applications. The failure of polymers and their composites are due to the tribological loading. In this context, one of the major tribological damage to polymer is by abrasives. Therefore, the wear behaviour of polymer composites when they are in contact with abrasives must be studied. One of the important abrasive tests with respect to polymers is three body test. Three body abrasive wear is the wear, where the abrasive particles are loose, move relative to one another and also rotate and slide across the wearing surface [1]. Three body abrasive wear is a common phenomenon in most of the engineering and agricultural components. Less attention was given to three body abrasive wear compared to two body abrasive wear. Therefore, study on three body abrasive wear behaviour of polymer composites is a must. Abrasive wear situations are noticed in vanes, gears, pumps, sewage and roll neck bearings in steel mills subjected to heat, shock loading, chute liners, coal and mineral ores, bushes and seals in agricultural and mining equipments have been received increasing attention [2]. In all these applications, multifunctional performance is required from a polymer material to uphold both mechanical and tribological loading. It is not possible by a homopolymer to meet the demands arising from the situation where both the properties are required. This made the material designer to depend on the methods of polymer modification to obtain the modified polymer. 
Methods of polymer modification includes blending of polymers, copolymerization and reinforcing of polymers [3]. The polymer blending is one of the effective method of improving the wear and frictional properties of homopolymer in the field of tribology in terms of cost effectiveness. It was reported from many researchers that friction and wear behaviour of polymer blends are the functions of blend composition and coefficient of friction. They concluded that the blend performance was better than the component polymer [4]. Wear is defined as the damage to the solid surface involving continuous loss of material due to the relative motion between the surfaces which are in contact. Abrasive wear is the important wear among all the types of wear because it contributes almost $60 \%$ of total cost of the wear [5]. The material removed by wear is mainly affected due to load, abrading distance, speed and the size of the abrasives [6-8]. Mechanical and three body abrasive wear behaviour of UHMWPE modified PP/PET blends were reported by N. Chand et al [9]. The abrasive wear characteristics of UHMWPE filled vinylester composites were reported by Cenna and others. [10]. The effect of fillers such as talc, $\mathrm{CaCo}_{3}, \mathrm{BaSO}_{4}$ and fly ash on the abrasive wear of polypropylene was reported by Sole and Ball [11]. They reported that the wear behaviour of blend is purely a function of blend composition. Further, they stated that the effect of abrasive on thermoplastics is very sensitive. Ratner and Lancaster models of abrasive wear behaviour can provide a good indication resistance of many polymeric materials to abrasion [12]. B N Ravi Kumar et al [13] studied the effect of abrasives on three body wear behavior of particulate filled Polyamide/Polypropylene Nano composites. They observed that inclusion of fillers in
PA66/PP blend had significant influence on the wear under varying abrading distances. Budinski [14] investigated the abrasion resistance of twenty-one types of plastics and concluded that polyurethane exhibited the better abrasion resistance. The least wear rate in abrasion against rough mild steel whereas high wear rate against coarse corundum paper of LDPE composites among eighteen polymers was reported by Evans [15]. Modeling the three-body abrasive wear of UHMWPE particle reinforced composites was studied [16, 17]. The effect of particle characteristics on three body abrasive wear was studied by Stachowiak et al [18]. They stated that rounded particles generated round craters and smooth grooves while angular particles produced sharp indents and narrow cutting grooves. The wear characteristics of thermoset composite under high stress three body abrasive was reported by Yousif and EI-Tayeb [19]. Commercial polymer based bearing materials generally incorporates fillers (CB, Bronze powder, $\mathrm{SiO}_{2}$, Silica, $\mathrm{SiC}$, Talc), fibers and solid lubricants (PTFE, $\mathrm{MOS}_{2}, \mathrm{Al}_{2} \mathrm{O}_{3}$ ) to improve the mechanical, tribological and thermal properties of base polymers. Polyamide 66 (PA66) is a highperformance thermoplastics polymer with good wear resistance and strength. Polypropylene (PP) is one among high strength polymer with good wear resistance and thermal stability properties. The concept of blending PA66 with PP (PA66/PP) was very rarely reported. In this connection, a blend of PA66/PP with different weight percentages: 95/5, 90/10, 85/15, 80/20, $75 / 25$ and $70 / 30$ have been selected and their systematic study for three body abrasion under different loading conditions is reported. The fine grain dry sand particles were used as third body abrasive along with rubber wheel and the

Table 1: Data and source of materials used in this study

\begin{tabular}{|c|c|c|c|c|c|c|}
\hline Material & Designation & Form & $\begin{array}{c}\text { Size } \\
(\boldsymbol{\mu m})\end{array}$ & Trade Name & Manufacturer & $\begin{array}{c}\text { Density } \\
\left(\mathbf{g} / \mathbf{c m}^{\mathbf{3}}\right)\end{array}$ \\
\hline Polyamide 66 & PA66 & Granules & --- & $\begin{array}{c}\text { Zytel 101L } \\
\text { NC010 }\end{array}$ & DuPont Co. Ltd & 1.14 \\
\hline Polypropylene & PP & Powder & 12 & $\begin{array}{c}\text { Grade } \\
\text { MP1000 }\end{array}$ & DuPont Co. Ltd & 0.9 \\
\hline
\end{tabular}


Lingesh et al., J. Mod. Mater.; Vol. 3, Issue 1, pp: 24-32, 2017

Table 2: Formulations of Composite blend PA66/PP

\begin{tabular}{|c|c|c|c|c|c|c|c|}
\hline \multirow[t]{2}{*}{ Composition } & \multirow[t]{2}{*}{$\begin{array}{c}\text { Material } \\
\text { ID }\end{array}$} & \multicolumn{2}{|c|}{$\begin{array}{c}\text { Weight } \\
\text { Percentage }\end{array}$} & \multirow[t]{2}{*}{ Composition } & \multirow[t]{2}{*}{$\begin{array}{l}\text { Material } \\
\text { ID }\end{array}$} & \multicolumn{2}{|c|}{$\begin{array}{c}\text { Weight } \\
\text { Percentage }\end{array}$} \\
\hline & & PA66 & PP & & & PA66 & $\mathbf{P P}$ \\
\hline $\begin{array}{c}\text { Blend } \\
\text { (PA66/PP) }\end{array}$ & $1 \mathrm{~T}$ & 95 & 5 & $\begin{array}{c}\text { Blend } \\
\text { (PA66/PP) }\end{array}$ & $4 \mathrm{~T}$ & 80 & 20 \\
\hline $\begin{array}{c}\text { Blend } \\
(\text { PA66/PP) }\end{array}$ & $2 \mathrm{~T}$ & 90 & 10 & $\begin{array}{c}\text { Blend } \\
(\text { PA66/PP) }\end{array}$ & $5 \mathrm{~T}$ & 75 & 25 \\
\hline $\begin{array}{c}\text { Blend } \\
\text { (PA66/PP) }\end{array}$ & $3 \mathrm{~T}$ & 85 & 15 & $\begin{array}{c}\text { Blend } \\
(\text { PA66/PP) }\end{array}$ & $6 \mathrm{~T}$ & 70 & 30 \\
\hline
\end{tabular}

specimen under test. The effect of abrading distance and load on wear volume and wear rate was studied and reported systematically. The worn surfaces are studied by using Scanning Electron Microscope (SEM) photographs.

\section{Materials and Methods}

Materials used in the present investigation and formulation of composite blend of PA66/PP in different weight percentages are tabulated in Table 1 and 2 respectively.

\subsection{Fabrication of Blends}

The polymers PA66 and PP were dried at $80^{\circ} \mathrm{C}$ for about 48 hours to remove moisture content. The materials were then thoroughly mixed in a mixer and the mixture was extruded using Barbender co-rotating twin-screw extruder (Make: CMEI, Model: 16CME, SPL, chamber size $\left.70 \mathrm{~cm}^{3}\right)$. The zonal temperature of the extruder chamber was zone1 $\left(220^{\circ} \mathrm{C}\right)$, zone2 $\left(235^{\circ} \mathrm{C}\right)$, zone $3\left(240^{\circ} \mathrm{C}\right)$, zone $4\left(265^{\circ} \mathrm{C}\right)$ and zone 5 $\left(270^{\circ} \mathrm{C}\right)$ respectively and the temperature at the die was set at $220^{\circ} \mathrm{C}$. The extrudates were obtained at a feed rate of $5 \mathrm{~kg} / \mathrm{hr}$. The cylindrical rod extrudates which were quenched in cold water are converted into pellets using Pelletizing machine. The pelletized extrudates were once gain heated and then subjected to injection moulding. The zonal temperatures of the barrel were zone $1\left(265^{\circ} \mathrm{C}\right)$ and zone $2\left(290^{\circ} \mathrm{C}\right)$ and mold temperature was $65^{\circ} \mathrm{C}$. The screw speed was set at 10-15 rpm followed by $700-800$ bar injection pressure. The injection time, cooling time and ejection time maintained during injection molding are 10, 35 and 2 s respectively. All the injection moulded specimens as per ASTM methods were inspected visually and those found defects are discarded to testing.

\subsection{Three Body Abrasive Wear Test}

Three body abrasive wear behaviour of PA66/PP blends were studied as per ASTM G65 using rubber wheel abrasion tester (RWAT) shown in Figure 1 (Magnum Engineers, Bangalore). The test sample was fixed to the abrasion tester. The rubber wheel which is one among the participating body is fixed in such way that there was no air gap between the specimen and the wheel. In the present study, Silica sand of AFS 60 grade (Density 2.4g/cc and knop hardness 875 ) was used as third body abrasive particles. The abrasive was collected in hopper and it is fed to the junction where the rubber wheel and specimen meet. Tests are conducted at a rotational speed of $209 \mathrm{rpm}$. The abrasive feed rate was $275 \pm 5 \mathrm{~g} / \mathrm{min}$. The sample was cleaned in ultrasonic device and then dried. Its initial weight was measured in high precision digital balance $(0.1 \mathrm{mg}$ accuracy, mettler, Toledo). The abrasives were introduced between the test

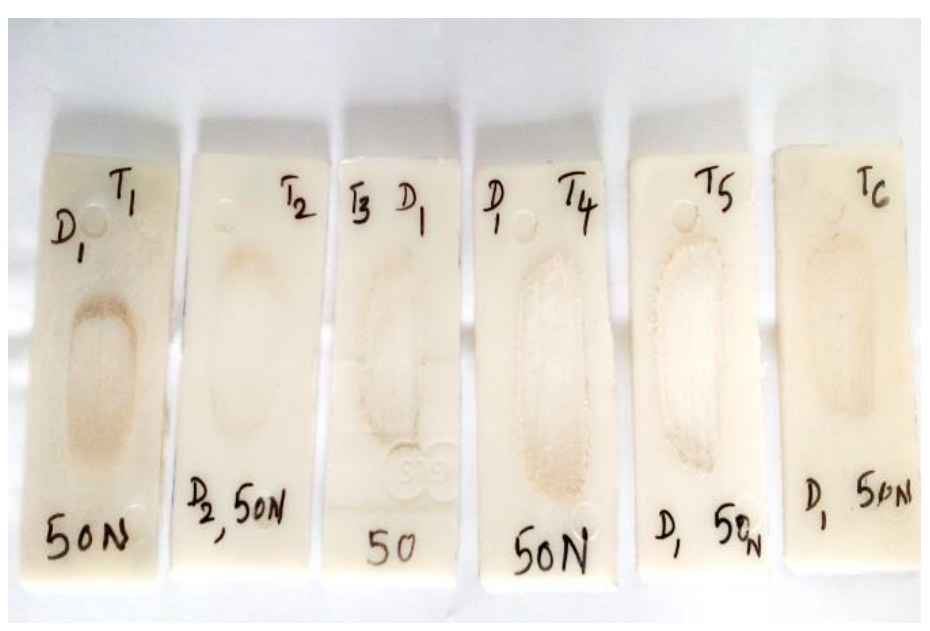

(a) 


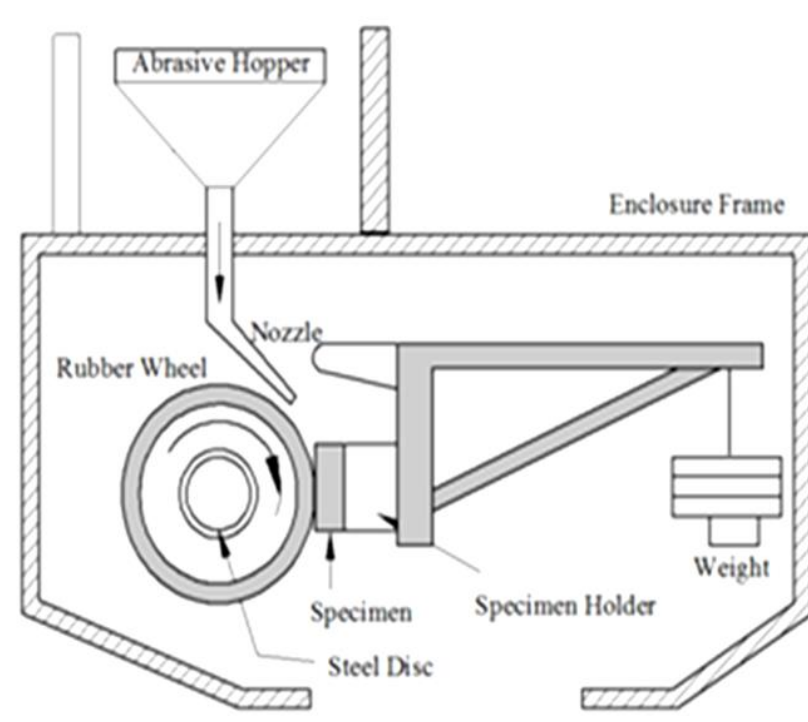

(b)

Figure 1: An Experimental set up used for three body abrasive wear system :(a) RWAT machine and (b) Tested specimen's photographs

specimen and rotating abrasive wheel composed of chlorobutyle rubber tyre (Hardness: Durometer-5A 58-62). The wheel rotates in same direction as that of abrasive flow. The abrasive flow was maintained uniformly for the better accuracy of results. The load of $50 \mathrm{~N}$ and $75 \mathrm{~N}$ were selected for the test with abrading distance ranging from $500-1500 \mathrm{~m}$. The velocity of rubber wheel was $2.5 \mathrm{~m} / \mathrm{s}$. When the specimen rubbed against rubber wheel through the medium of abrasive particles, loss of weight occurs due to high friction and contact stresses introduced during interaction. The final weight of specimen was measured. The abrasive wear was measured by the loss in weight $(\mathrm{W})$ which is then converted into wear volume by using the experimentally determined density (@). The wear volume, $\delta \mathrm{V}$ and specific wear rate, Ks was calculated by using the following formula. The Wear volume, $\delta \mathrm{V}=\mathrm{W} / \varrho$ $\mathrm{mm}^{3}$. The specific wear rate, $\mathrm{K}_{\mathrm{s}}=\delta \mathrm{V} /(\mathrm{F} \times \mathrm{D})$ $\mathrm{mm}^{3} / \mathrm{N}-\mathrm{m} . \mathrm{F}$ is the load in Newton and $\mathrm{D}$ is the abrasive distance in meters.

\subsection{Scanning Electron Microscope}

The worn surfaces of the abraded specimens were studied by using Scanning Electron Microscope (Joel JSM - 480 Microscope) photographs with proper magnification, whose detail is given in section 3.2 (Analysis of worn surfaces).

\section{Results and Discussion}

\subsection{Abrasive Wear Volume and Specific Wear Rate}

The effect of abrading distance on wear volume of PA66/PP blends at different loads with a velocity of $2.5 \mathrm{~m} / \mathrm{s}$ are presented in Figure 2 (a) and 2 (b) respectively.

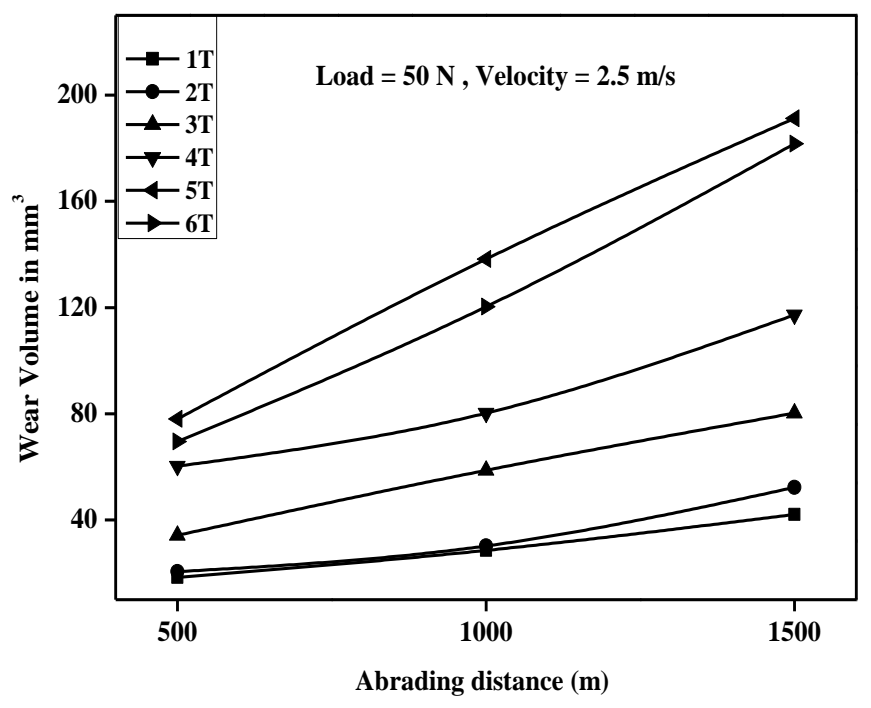

(a)

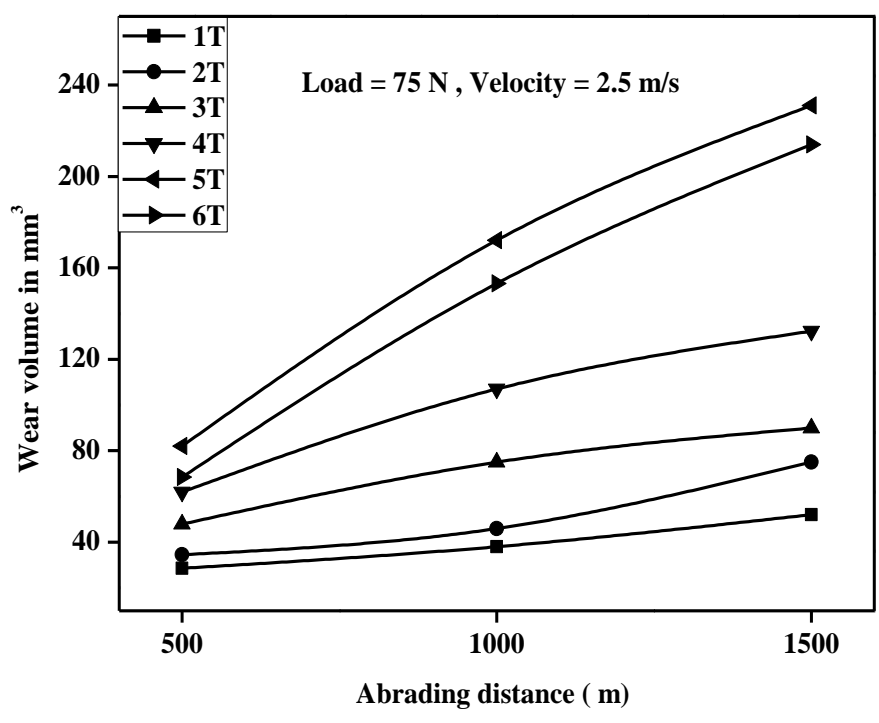

(b)

Figure 2: Effect of abrading distance on wear volume of PA66/PP blend: (a) Load $=50 \mathrm{~N}(\mathrm{~b})$ Load $=75 \mathrm{~N}$ 
The behavior of composites followed almost the linear trend. It is clear from the figure that wear volume is a function of load, abrading distance and composition of blends tested. Introduction of PP into blend in steps of $5 \mathrm{wt}$. \% increases the wear volume loss. The reduction in wear volume starts at higher loading of PP in blend. The highest wear volume loss is for $75 / 25 w t$. \% of PA66/PP, whereas the least volume loss was exhibited by $95 / 5$ wt. \% PA66/PP blend. The same trend was observed for both the loads. This is purely attributed to the crystalline effect of PP. Initially, at low content of PP in blend, the wear behavior was in the hands of PA66 which is very much resistant to wear volume loss. But as the content of PP in blend increases, the material becomes brittle and impaired the mechanical strength. This weakens the response effect of blend to wear against the counter parts. For a load of $50 \mathrm{~N}$, minimum abrading distance with minimum percentage of $\mathrm{PP}$ in the blend, the wear volume loss of PA66/PP was $18.36 \mathrm{~mm}^{3}$. For the same test condition with highest percentage of $\mathrm{PP}$, the wear volume is $69.56 \mathrm{~mm}^{3}$ which is around $278 \%$ increase. The compatibility between PA66 and PP was established by compatibilizer MagH. Similarly, 161\% increase in wear volume was noticed for the same testing conditions with maximum abrading distance by higher loading of PP. It is concluded that, higher loading of PP will enhance the wear resistance of blend. The gain of wear volume loss with higher abrading distance was attributed to the abrasive particles which could interact with the soft polymeric materials thereby offering the wear resistance against the tested load. The formation of dry transfer film of PA66 on the rubber wheel could slide the wheel without any volume loss. Similar observations were made for load of $75 \mathrm{~N}$. The volume loss of the material between higher and lower loading of PP with minimum and maximum abrading distance was appreciably small when compared to $50 \mathrm{~N}$. The same trend was repeated for higher load also. The wear volume loss was of the order $5 T>6 T>4 T>3 T>2 T>1 T$.

The Effect of abrading distance on specific wear rate of PA66/PP blends at different loads are shown in Figure 3 (a) and 3 (b).

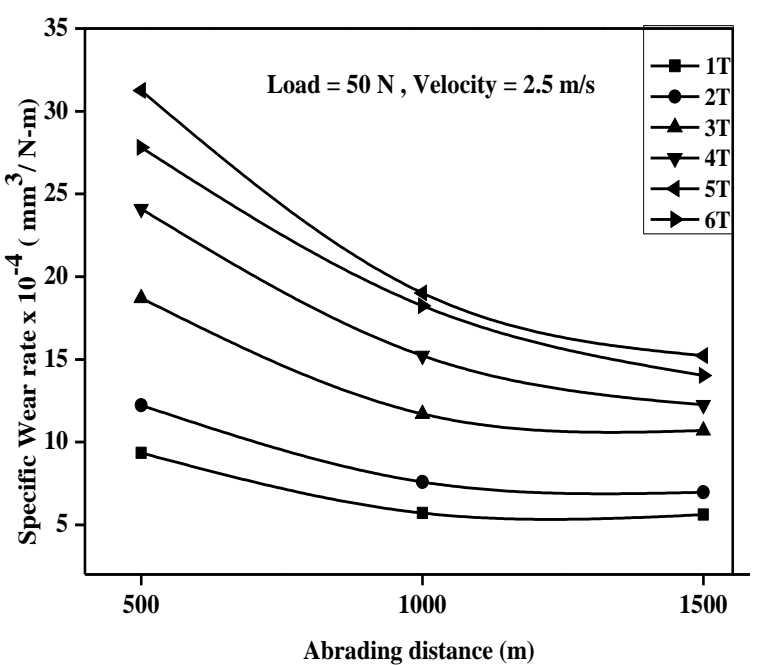

(a)

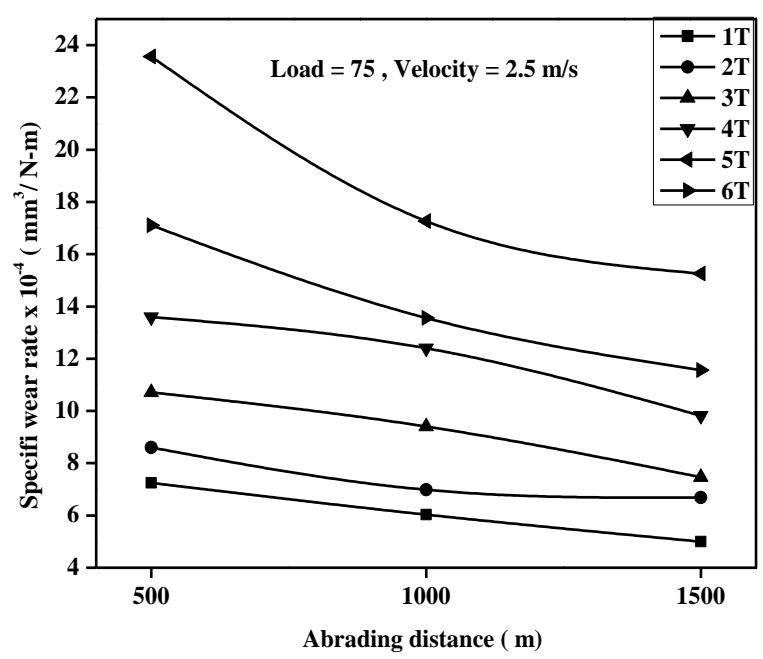

(b)

Figure 3: Effect of abrading distance on specific wear rate of PA66/PP blends:(a) $50 \mathrm{~N}$ and (b) $75 \mathrm{~N}$

The specific wear rate varies from $9.34 \times 10^{-4}$ to $31.25 \times 10^{-4} \mathrm{~mm}^{3} / \mathrm{N}-\mathrm{m}$ for a load of $50 \mathrm{~N}$. The specific wear rate varies from $7.24 \times 10^{-4}$ to 23.56 $\mathrm{x} 10^{-4} \mathrm{~mm}^{3} / \mathrm{N}-\mathrm{m}$ for a load of $75 \mathrm{~N}$. There was a decrease in the range of specific wear rate for higher load. This can be attributed to the functional relation between wear rate and load. However, 95/5 wt. \% of PA66/PP blend had the best specific wear resistance. Sole and Ball [11] studied the effect of mineral fillers like talc, fly ash, $\mathrm{CaCO}_{3}, \mathrm{BaSO}_{4}$ on the abrasive wear resistance of Polypropylene. The present studies are in good agreement with the literature reported. Furthermore, the purpose of adding fillers into the polymer matrix is to increase the mechanical 
Table 3: Mechanical properties of PA66/PP blend

\begin{tabular}{|c|c|c|c|c|c|c|c|c|}
\hline Properties & Units & $\begin{array}{c}\text { ASTM } \\
\text { Method }\end{array}$ & $\mathbf{1 T}$ & $\mathbf{2 T}$ & $\mathbf{3 T}$ & $\mathbf{4 T}$ & $\mathbf{5 T}$ & $\mathbf{6 T}$ \\
\hline $\begin{array}{c}\text { Tensile strength } \\
(\boldsymbol{\sigma})\end{array}$ & $\mathrm{MPa}$ & $\mathrm{D} 638$ & 61.5 & 47.5 & 39.5 & 34.5 & 33.5 & 21.5 \\
\hline $\begin{array}{c}\boldsymbol{\%} \text { Elongation } \\
(\boldsymbol{\varepsilon})\end{array}$ & $\mathrm{mm}$ & $\mathrm{D} 638$ & 19.5 & 18.5 & 14 & 12 & 9.5 & 8.5 \\
\hline $\mathbf{( \sigma \boldsymbol { \varepsilon } ) \text { factor }}$ & $\mathrm{N}-\mathrm{mm}$ & & 1199.25 & 878.75 & 553 & 414 & 318.25 & 182.75 \\
\hline $\mathbf{1} /(\boldsymbol{\sigma} \boldsymbol{\varepsilon})$ factor & & & $8.36 \times 10^{-4}$ & $11.3 \times 10^{-4}$ & $18 \times 10^{-4}$ & $24.15 \times 10^{-4}$ & $31.4 \times 10^{-4}$ & $54.7 \times 10^{-4}$ \\
\hline
\end{tabular}

behavior, but their effect on the wear behavior is not beneficial. The adding of non-thermoplastics fillers into the blend had the detrimental effect on the abrasive wear behavior of the polymer [21]. The effect of fillers on the mechanical behavior is most appreciable, but there was a reduction in elongation of polymer composites. The model proposed by Ratner and Farberova [23] state that the rate of material removal is inversely proportional to the product of stress and strain at rupture. The product of strength and strain at rupture is the controlling factor for the abrasive wear behavior of filled polymer composites. According to them, reduction in elongation at break is a key factor in influencing the abrasive wear resistance of filled polymer composite. The mechanical properties of PA66/PP blends are reported in the Table 3. For the composite blends tested, the volumetric loss of a material is inversely proportional to the product of stress and strain at rupture $(1 / \sigma \varepsilon)$. The wear resistance of studied polyblend is directly proportional to ' $\sigma \varepsilon$ ' factor. Therefore, the experimental results are in good agreement with the work of researchers $[8,22,23]$. Even though, $70 / 30$ wt. $\%$ PA66/PP exhibited least ' $\sigma \varepsilon$ ' factor, the abrasion resistance was better than 75/25 wt. \% PA66/PP. This can be due to hard nature of PA66/PP composite. The specific wear rate data of studied polymer blends under multi pass three body abrasive wear reveals that it could increase with increase in abrading distance, normal load and decreases with higher loading of PP in blend.

\subsection{Analysis of Worn Surfaces}

The correlation of data for different testing conditions can be justified by studying the SEM Micrographs of worn surface of composite blend PA66/PP. The SEM photographs of abraded surfaces of different weight percentage of $\mathrm{PP}$ in blend are shown in Figures 4-6. The worn surface of specimen $95 / 5 \mathrm{wt}$. \% of PA66/PP blend under the load of $75 \mathrm{~N}$ at minimum and maximum abrading distance are presented in Figure 4 (a) and 4 (b).
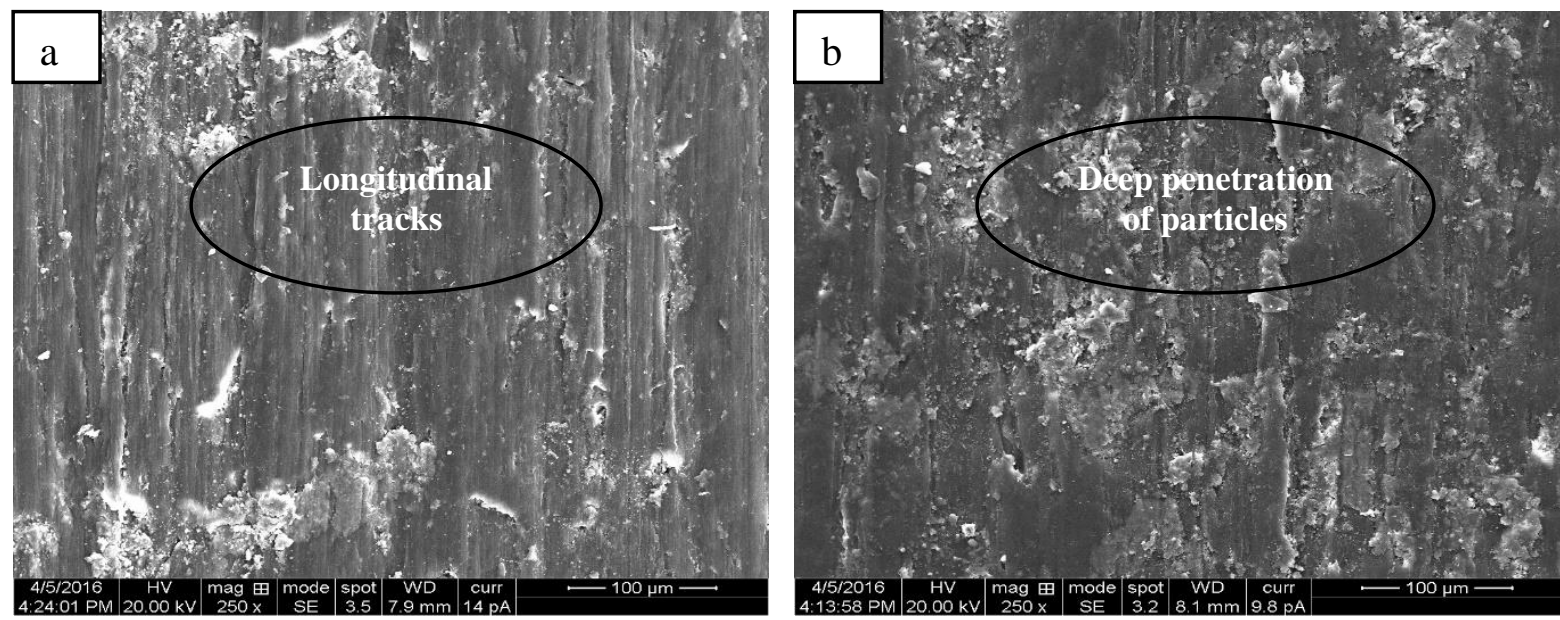

Figure 4: SEM photographs of 95/5 wt. \% of PA66/PP blends at $75 \mathrm{~N}:$ (a) $500 \mathrm{~m}$ and (b) $1500 \mathrm{~m}$ 

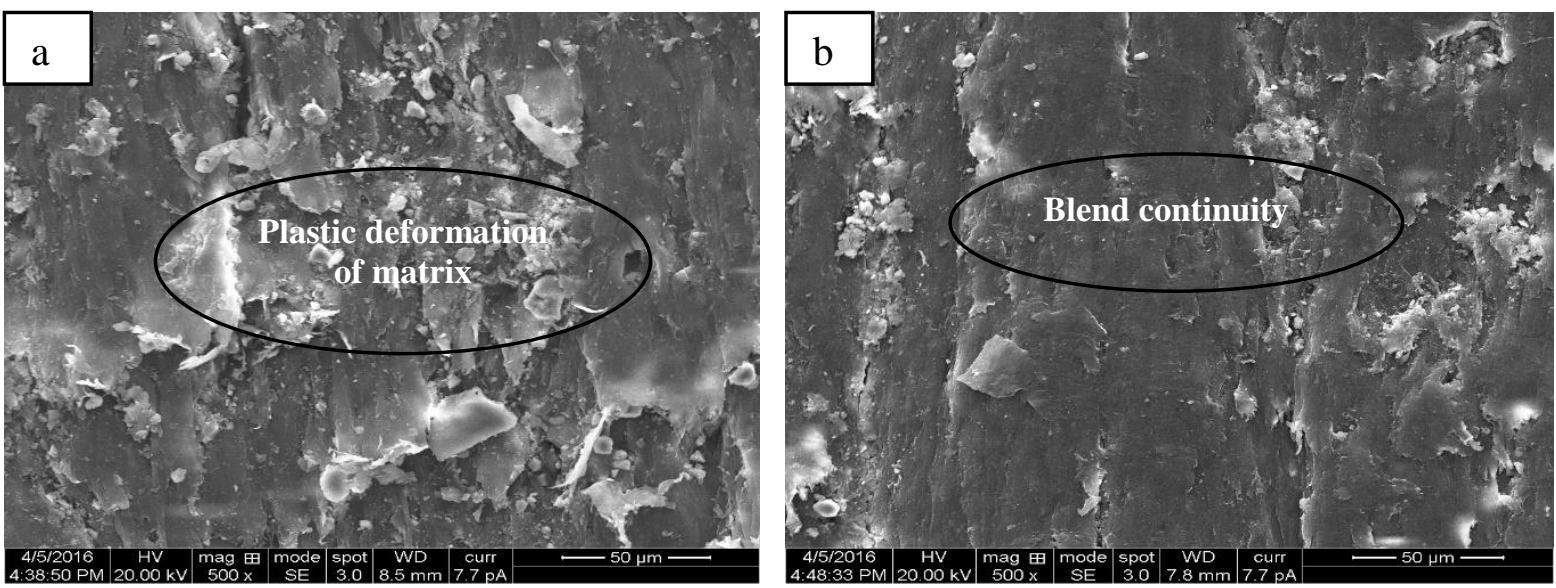

Figure 5: SEM photographs of 80/20 wt. \% of PA66/PP blends at $75 \mathrm{~N}:$ (a) $500 \mathrm{~m}$ and (b) $1500 \mathrm{~m}$
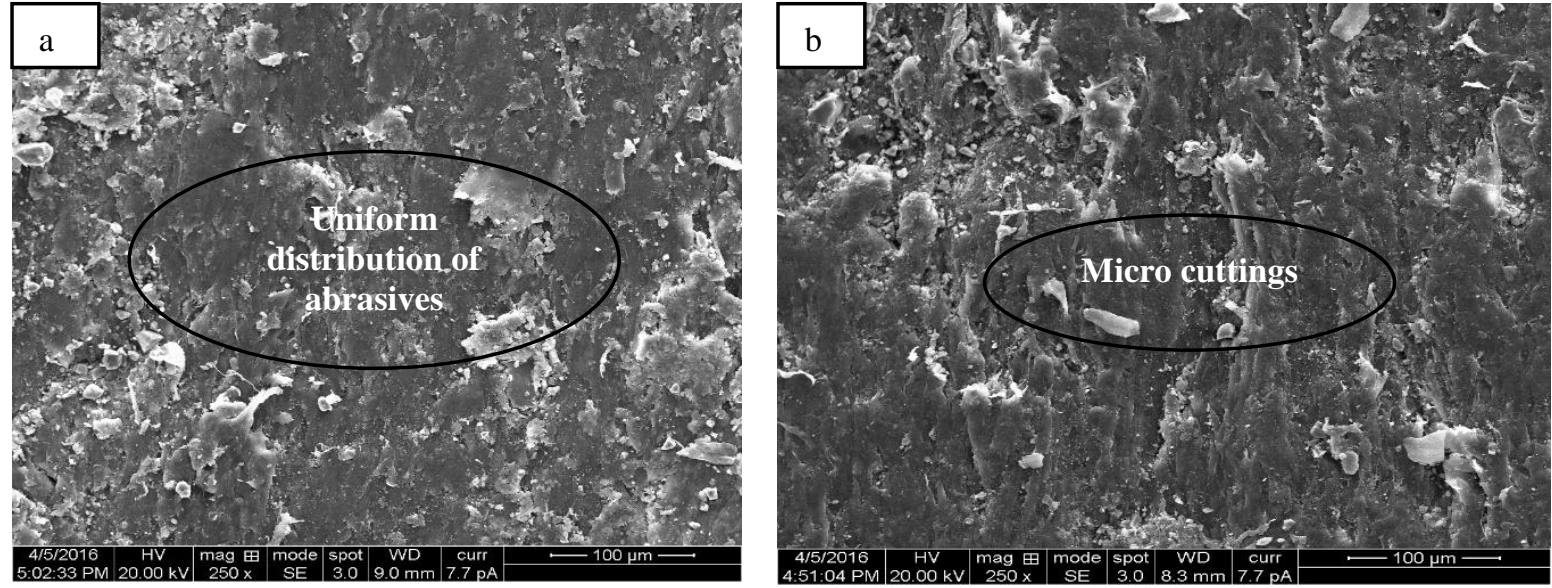

Figure 6: SEM photographs of 70/30 wt. \% of PA66/PP blends at $75 \mathrm{~N}:$ (a) $500 \mathrm{~m}$ and (b) $1500 \mathrm{~m}$

SEM photographs of $95 / 5$ wt. $\%$ of blends at lower abrading distance clearly showed the presence of wear debris and damage of matrix. The different angular shaped and random sized hard abrasive sand particles penetrate into the surface of PA66/PP blend, subsequently removing material from the surface by micro ploughing process. During this process, the polymer matrix deformed plastically before being separated owing to the additional micro cutting. The soft polymer matrix damaged severely due to the interaction of polymer with abrasives and wheel for long duration $(1500 \mathrm{~m})$. During this process, the abrasive sand particles dip into the surface of soft polymer, micro ploughing the material repeatedly till the wear debris generates and interacts with the process of abrasive wear there by volume loss. At lower abrading distance $(500 \mathrm{~m}$, Figure $4 \mathrm{a})$, the abrasive wear of material was governed by polyamide 66 due to low percentage of PP. During this process, matrix micro cutting generates the wear debris which would interact with hard sand particles during the three-body abrasive wear. The matrix wear, abrasive's wear and repeated cutting along with micro ploughing was clearly shown in Figure 4 (a). At higher abrading distance, heavy damage of matrix due to combined action of wheel and abrasive sand particles promotes high percentage of material loss. It was evident from the fact that the relative motion of wheel, surface contact of the material and flow rate of sand particles are the key factors which can promote the abrasive wear behavior. At low abrading distance, the wheel contacts the specimen surface with high velocity along with the sand particles. In the beginning, the frictional force required to rub the material was high and later it decreases due to the formation of uniform film track on the surface. During this situation, the sand particles and debris from the material would collect at the center of track and acts as abrasion particles again 
for the process. This was witnessed in Figure 4(b). The SEM photographs of $80 / 20$ wt. $\%$ of PA66/PP blend at lower and higher abrading distance under the action of $75 \mathrm{~N}$ is presented in Figure 5 (a) and 5 (b). The heavier deep parallel grooves along with longitudinal cracks due to the action of abrasives are seen. The repetitive plugging of material results in the loss of material due to heavier matrix damage and also deep parallel furrows are shown in Figure 5 (a). At higher abrading distance $(1500 \mathrm{~m})$, the extruded furrows in large scale were seen in Figure 5 (b). The repetitive micro cutting with the help of abrasives and subsequent loss of material due to high stress introduced by the rubber wheel along with the abrasive inserts directs the material to wear more. The deep contact stresses introduce the micro cracks causing surface fatigue. Figure 6 (a) and 6 (b) shows the worn surface of 70/30 wt. $\%$ of $\mathrm{PA} 66 / \mathrm{PP}$ blend at lower and higher abrading distance under the load of $75 \mathrm{~N}$. At low abrading distances, shallow wear grooves were observed due to more percentage of PP in the blend. Less damage of matrix was observed, hence low quantum of wear. Uniform wear scars were noticed in the photographs. Smooth grooves are seen with little wear debris. At higher abrading distance, the concentration of wear debris along with the extruded filaments of debris was shown in Figure 6 (b). Heavier matrix damage was occurred due to micro cutting. Matrix furrows and deburred abrasive particles were collected at the region which was clearly shown in Figure 6 (b). Repetitive ploughing, long micro cutting and fatigue are the major mechanisms involved in the abrasive behavior of PA66/PP blends.

\section{Conclusions}

This research study reveals that PA66/PP is a poor abrasive wear resistance under lower loading of PP. The specific wear rate of blend increases with increase in abrading distance, load and decreases with higher loading of PP. Repetitive ploughing, long micro cutting and fatigue are the major mechanisms involved in three body abrasive wear of PA66/PP blend.

\section{How to Cite this Article:}

B. Lingesh, B. Ravikumar, and B. Rudresh, "Three Body Abrasive Wear Behaviour of Polyamide 66/ Polypropylene (PA66/PP) Thermoplastic Blends", J. Mod. Mater., vol. 3, no. 1, pp. 24-32, Feb. 2017. doi: 10.21467/jmm.3.1.24-32

\section{References}

[1] Zhaobin Chen, Xujun Liu, Renguo Lu, Tongsheng Li, "Mechanical and tribological properties of PA66/PPS blend. III.Reinforced with GF", J. Appl. Polym. Sci., Vol.102, pp.523-529, 2006.

[2] Yamaguchi Y, "Tribology of plastic materials", Elsevier, New York, Tribology series 16,pp.143,1990.

[3] Hashmi S. A. R, Neogi S, Pandey A,Chand N, "Sliding wear of PP/UHMWPE blends: effect of blend composition", Wear, Vol.247,pp.9-14, 2001.

[4] M. Palabiyik, S. Bahadur, "Tribological studies of polyamide 6 and high-density Polyethylene blends filled with PTFE and copper oxide and reinforced with short glass fibers", Wear, Vol.253,pp.369-376, 2002.

[5] Yelle H, Benabdallah H, Richards H, "Friction and wear of Polyethylene and Nylon blends", Wear, Vol.149, pp.341- 352, 1991.

[6] B. Suresha, G. Chandramohan, Siddaramaiah, T. Jayaraju, "Influence of cenosphere filler additions on the three-body abrasive wear behavior of glass fiber-reinforced epoxy composites ", J. Polym Comp., Vol. 29 (3), pp. 307-312, 2008.

[7] B. Suresha, G.Chandramohan, "Three body abrasive wear behavior of particulate filled vinyl ester composites", J. Mater. Process. Tech., Vol. 200, pp. 306-311, 2008

[8] A. P. Harsha, U. S. Tewari, "Two and three body abrasive wear behavior of polyaryletherketone composites", J. Polym.Test, Vol. 22, pp.403-418, 2002.

[9] Naveen chand, A.M Naik, H.K Khaira, "Development of UHMWPE modified PP/PET blends and their mechanical and abrasive wear behavior", Polym. Comp, Vol. 28 (2), pp. $267-$ 272, 2007.

[10] A. A. Cenna, J.Doyle, N.W.Page, A. Beehag, P.Dastoor, "Wear mechanisms in polymer matrix abraded by bulk solids", Wear, Vol. 240, pp. 207-214, 2000.

[11] B.M.Sole, A.Ball, "On the abrsive wear behavior of mineral filled polypropylene”, Tribol. Int.Vol. 29, pp. 457-465, 1996.

[12] J.K. Lancaster, "Abrasive wear of polymers", Wear, Vol. 14, pp. 223-239, 1969.

[13] B.N.Ravikumar, B.Suresha, M. Venkataramareddy, "Effect of abrasives on three body wear behavior of particulate filled polyamide66/polypropylene nano composites",Comp. Inter, Vol. 17, pp.113-216, 2010.

[14] K.G.Budinski, "Resistance to particle abrasions of selected plastics", Wear, Vol. 203-204, pp.303-309, 1997

[15] D.C. Evans, J. K. Lancaster, “The wear of Polymers”, Treatise on Mater. Sci. and Tech.,Vol. 13, pp. 85-139, 1979.

[16] Navin chand, Ajay Naik, Somit Neogi, "Three body abrasive wear of short glass fiber polyester composites", Wear, Vol. 242, pp. 38-46, 2000.

[17] A.A. Cenna, S. Allen, N. W. Page, P. Dastoor," Modeling the three body abrasive wear of UHMWPE particle reinforced composites ", WearVol. 254, pp. 581-588, 2003.

[18] G.B.Stachowiak, G.W. Stachowiak, "The effect of particulate characteristics on three body abrasive wear", Wear, Vol. 249, pp. 201-207, 2001. 
[19] B.F.Yousif, N.S.M.EI- Tayeb, "Wear characteristics of thermoset composites under high stress three body abrasive", Tribo. Intl. Vol. 43 (12), pp. 2365-2371, 2010.

[20] B. Suresha, G. Chandra Mohan, Siddaramaiah, Kunigal N Shiva Kumar, Mohammed Ismail, "Mechanical and three body abrasive wear behavior of three dimensional glass fabric reinforced vinyl ester composites", J. Mater.Sci. Eng. AVol. 480, pp. 573-579, 2008.

Publish your research article in AIJR journals-

$\checkmark \quad$ Online Submission and Tracking

$\checkmark$ Peer-Reviewed

$\checkmark$ Rapid decision

$\checkmark \quad$ Immediate Publication after acceptance

$\checkmark$ Articles freely available online

$\checkmark \quad$ Retain full copyright of your article.

Submit your article at journals.aijr.in
[21] B. Suresha, B. N. Ravi Kumar, "Two body abrasive wear behavior of particulate filled polyamide 66/ Polypropylene nano composites", J. Appl. polym. Sci. Vol. 119, pp. 22922301, 2011

[22] Lancaster J. K, Polym. sci., A material science hand book, North Holland, Amsterdam, 1972.

[23] Ratner S. N, Fraberova I. I., Radynekevich O. V, Lure E. G, Sov Plast, Vol. 7, pp. 37, 1964.

Publish your books with AIJR publisher-

$\checkmark$ Publish with ISBN and DOI.

$\checkmark$ Publish Thesis/Dissertation as Monograph.

$\checkmark$ Publish Book Monograph.

$\checkmark$ Publish Edited Volume/ Book.

$\checkmark \quad$ Publish Conference Proceedings

$\checkmark \quad$ Retain full copyright of your books.

Submit your manuscript at books.aijr.org 